\title{
La Constitución de Cádiz en el centro de Cuba: el ayuntamiento constitucional de la ciudad de Sancti Spíritus (1812-1814)*
}

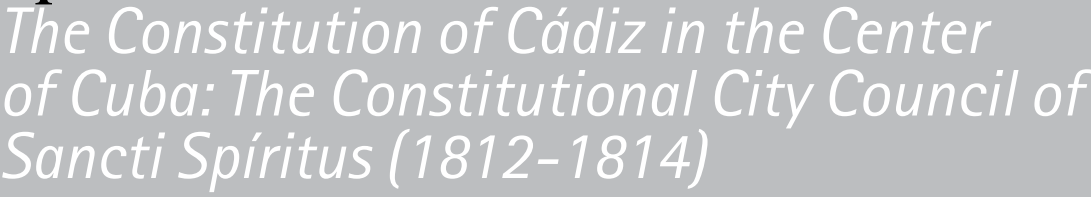

\section{Yuri Fernández Viciedo***}

\section{RESUMEN}

El presente artículo aborda la vigencia de la Constitución de Cádiz en Cuba entre 1812 y 1814, a partir de un estudio de caso: el ayuntamiento constitucional de la ciudad de Sancti Spiritus. Se desarrolla una caracterización de la actividad del ayuntamiento constitucional erigido en esta ciudad en 1812, hasta su clausura en 1814. Sobre la base del análisis, se someten a critica las tesis historiográficas tradicionales sostenidas desde Cuba, respecto a la escasa vigencia del constitucionalismo doceañista en la isla. Los criterios emitidos se sustentan en los cuadernos capitulares del ayuntamiento de la ciudad de Sancti Spiritus. A partir de ello se reevalúa el papel de los gobiernos locales existentes en Cuba para la puesta en vigor de los postulados constitucionales gaditanos.

PALABRAS CLAVE: Constitución de Cádiz, Cuba, ayuntamiento constitucional, Sancti Spiritus, alcaldes constitucionales.

\begin{abstract}
This article addresses the state of being in force of the Constitution of Cádiz in Cuba between 1812 and 1814, based on a case study: The Constitutional City Council of the City of Sancti Spiritus. A characterization of the activity of the Constitutional City Council erected in this city in 1812, until its closure in 1814. On the basis of the analysis, the traditional historiographical thesis sustained from Cuba is subjected to criticism, with respect to the little validity of the Doceañista Constitutionalism in the island. The criteria rendered is based on the Chapter Notebooks of the city council of Sancti Spiritus. Based on this, the role of existing local governments in Cuba for the implementation of the constitutional postulates of those of the peoples of Cadiz are re-evaluated.
\end{abstract}

KEY WORDS: Constitution of Cádiz, Cuba, Constitutional City Council, Sancti Spiritus, Constitutional Mayors.

\footnotetext{
* Artículo de investigación. Recibido el 5 de septiembre de 2017 y aceptado para su publicación el 13 de junio de 2018.

** Profesor en la Universidad Central "Marta Abreu" de Las Villas, Cuba. (yfviciedo@uclv.cu) orcid.org/0000-0002$5162-7378$
} 


\section{SUMARIO}

1. Introducción

2. Sancti Spíritus en el tiempo y la Constitución de Cádiz

3. Primera elección de cargos e intentos de sabotaje

4. El bienio constitucional para el ayuntamiento de Sancti Spíritus

\section{Introducción}

El recibimiento de La Pepa en América estuvo estrechamente relacionado con las características sociopolíticas de cada territorio, así como con los intereses particulares de sus respectivas oligarquias. De tal manera, un mapa de su recepción americana superaría con creces los objetivos del presente estudio. Más allá de su debatida vigencia real durante sus dos promulgaciones, la Constitución de Cádiz fue, para la mayoría de la América insurgente, uno de los referentes legislativos sobre los cuales se apoyaron los primeros procesos constituyentes posindependentistas. ${ }^{1}$

La presencia de la Constitución española de 1812 en Hispanoamérica produjo actitudes diversas y reacciones contradictorias. Éstas oscilaron entre el rechazo expreso, el desacato, la indiferencia y el respaldo partidista. Para Fernández Sarasola, la Constitución de Cádiz abrió el camino del constitucionalismo a la mayoria de los territorios americanos bajo soberanía española, pero su implantación no tuvo la misma intensidad en todos los territorios. En su opinión, la reticencia de los virreyes a su aplicación y el estado de insurgencia existente conspiraron en contra de su efectividad en la mayor parte de Hispanoamérica. De hecho, en su criterio más concluyente, la propia Constitución acabaría por colaborar con el derrumbe ideológico e institucional del poder español en tierras americanas. ${ }^{2}$

Se puede apreciar un criterio ligeramente distinto en Néstor Pedro Sagués, para quien: "la Constitución de Cádiz fue formalmente acatada en dos de los cuatro virreinatos existentes en la época (Perú y México), y en partes de los otros dos (Nueva Granada y Río de la Plata) y en ciertas capitanías generales, y en

\footnotetext{
${ }^{1}$ Véase Chust, Manuel, "La revolución bihemisférica de la Constitución de 1812", Teoría y Derecho, núm. 10, p. 115.

2 Fernández SARASOla, IGNACIO, "La Constitución española de 1812 y su proyección europea e iberoamericana", Fundamentos. Cuadernos monográficos de Teoría del Estado, Derecho Público e Historia Constitucional, núm. 2. Disponible en: http://www.uniovi.es/constitucional/fundamentos/segundo.
} 
la Audiencia de Quito". ${ }^{3}$ En el caso de México, Ferrer Múñoz señaló que no prosperó la alianza entre el liberalismo peninsular y los partidarios del autonomismo americano. ${ }^{4}$ Era difícil llevar a la práctica el principio constitucional de igualdad entre todos los españoles de ambos hemisferios, debido al estado de insurgencia que siguió al grito de Dolores. ${ }^{5}$

Una posible clave que contribuiría a la reconstrucción del rompecabezas de Cádiz, en América, podría derivarse del impacto constitucional en las pequeñas localidades. La entonces Capitanía General de Cuba, una excepción de fidelidad dentro del conglomerado insurgente hispanoamericano, podía proporcionar elementos afines a este propósito.

La vigencia de la Constitución de Cádiz en Cuba ha sido objeto de frecuentes negaciones a lo largo de casi dos centurias. Durante el siglo XIX, su tránsito por la isla fue abordado desde posturas de diatriba y, en menor medida, de simpatía. En 1842, Jacobo de la Pezuela sostenía que el texto constitucional "no había ocasionado más que males", ${ }^{6}$ mientras Justo Zaragoza calificaba al periodo constitucional como "el dominio del absurdo".?

En la obra del autor criollo, Pedro José Guiteras, se encuentran criterios similares, aunque con ligeras contradicciones. En 1866 expresaba que la misma era "contraria al carácter e ideas reinantes y con principios anárquicos". Curiosamente, en la misma página, afirmaba que en Cuba "tocó el pueblo los beneficios de la libertad mezclados con las amarguras de la licencia". ${ }^{8}$ Dos años antes del inicio de la guerra de independencia de Cuba, esta afirmación ponderada acerca del hecho constitucional gaditano en la isla no sólo intriga, sino que también evidencia la influencia del partidismo político en las opiniones historiográficas de la época. Pezuela y Zaragoza no sólo eran peninsulares, sino también partidarios del integrismo.

Una década atrás, el propio Guiteras había sentenciado que, con la Constitución de 1812, Cuba había disfrutado "las ventajas que reportan los pueblos de las instituciones basadas en los principios de la intervención popular en la administración de los negocios públicos". ${ }^{9}$ Rafael Montoro, en el prólogo a Los antiguos diputados de Cuba, sostenía que: "Hablar de derechos individuales y

\footnotetext{
3 Sagués, Nestor Pedro, "La proyección de la Constitución de Cádiz en las Américas", X Congreso de la Asociación de Constitucionalistas de España "Las huellas de la Constitución de Cádiz", 26 y 27 de enero, 2012, p. 11. Disponible en: http://www.acoes.es/congresoX/documentos/PONENCIASAGUESCADIZENAMERICANESTORSAGUES.pdf.

${ }^{4}$ Ferrer Muñoz, Manuel, La Constitución de Cádiz y su aplicación en la Nueva España, México, unam, 1993, pp. 17-18.

${ }^{5}$ Ferrer Muñoz, Manuel, La Constitución de Cádiz y su aplicación en la Nueva España, México, unam, 1993, p. 28.

${ }^{6}$ Pezuela, JaCoBo de LA, Ensayo histórico de la Isla de Cuba, Nueva York, Imprenta Española de R. Rafael, 1842, p. 452.

7 Zaragoza, Justo, Las insurrecciones en Cuba, tomo 1, Madrid, Imprenta Manuel G. Hernández, 1872-1873, p. 260.

${ }^{8}$ Guiteras, Pedro José, Historia de la Isla de Cuba, volumen 2, La Habana, Imagen Contemporánea, 2005, p. 78.

${ }^{9}$ Guiteras, Pedro José, Cuba y su gobierno. Con un apéndice de documentos históricos, Londres, Imprenta de C. Wood, 1853, p. 12.
} 
de vida local superiores a todo poder [...] era cosa desconocida en aquel periodo de irreflexivo entusiasmo y de sublime inesperiencia [sic]". ${ }^{10}$

La tradición historiográfica del siglo xx no se mostró distinta en sus opiniones, en las que primó la tendencia a minimizar in extremis la vigencia y efectos del texto constitucional sobre la isla. Ramón Infiesta sostuvo que la carta constitucional "no se dejó sentir demasiado en Cuba", ${ }^{11}$ mientras Hernández Corujo afirmó que el sistema político gaditano "no iba a tener en la práctica política de la isla su perfecta e igual aplicación”. ${ }^{12}$ Por su parte, Julio Carreras sentenció que la misma "rigió en su primera etapa de un modo teórico". ${ }^{13}$ En esa dirección, Rolando Rodríguez sostiene que, con la Constitución, "no se había satisfecho a nadie". ${ }^{14}$

Como corolario de esta línea historiográfica, Julio Fernández Bulté, autor de uno de los manuales de historia del derecho usados en las universidades cubanas, obvió hacer referencia a cualquier incidencia de este texto constitucional sobre Cuba. Este enfoque trasciende al siglo xxI. Olga Portuondo ha sostenido que, con la Constitución gaditana, "no hubo ningún beneficio económico [...] ni logros en el terreno de la política”, afiliándose al criterio decimonónico de Jacobo de la Pezuela. ${ }^{15}$

Otro autor cubano, Serio Guerra, ha circunscrito su visión acerca de la vigencia de la Constitución doceañista en la isla, únicamente, a su recepción habanera. En su opinión, la Constitución de Cádiz debió ser motivo de alarma e inquietud entre los hacendados y esclavistas criollos quienes, asustados por el debate abolicionista que se promovió en las cortes durante 1811, "llegaron incluso a valorar, por primera vez, la anexión a Estados Unidos”. ${ }^{16}$ Esta opinión parcial -que se correspondería con el periodo constituyente, pero no con la etapa constitucional- no alcanza a explicar lo ocurrido en la isla durante ese lapso.

En una actitud contrapuesta, Reinaldo Suárez Suárez ha enarbolado la tesis de que, en este primer periodo de vigencia, la Constitución de Cádiz “catalizó un adelanto significativo”, con efectos directos sobre el renacimiento

\footnotetext{
${ }^{10}$ Valdés Dominguez, Eusebio, Los antiguos diputados de Cuba y apuntes para la Historia Constitucional de esta Isla, La Habana, Imprenta El Telégrafo, 1879, p. xxx.

${ }^{11}$ Infiesta, Ramón, Historia Constitucional de Cuba, La Habana, Cultural, 1951, p. 39.

${ }^{12}$ Hernández Corujo, Enrioue, Historia Constitucional de Cuba, tomo 1, La Habana, Compañía Editora de Libros y Folletos, 1960, p. 74.

${ }^{13}$ Carreras, Julio, Historia del Estado y el Derecho en Cuba, La Habana, Pueblo y Educación, 1989, p. 88.

${ }^{14}$ Rodriguez, Rolando, Cuba: la forja de una nación. Despunte y epopeya, La Habana, Ciencias Sociales, 2005, p. 51.

${ }^{15}$ Portuondo Zúñıga, Olga, Cuba. Constitución y liberalismo, tomo 1, Santiago de Cuba, Oriente, 2008, pp. 103-104.

${ }^{16}$ Guerra Vilaboy, Sergio, "La Constitución Gaditana en Cuba: 1812-1823", en La Constitución de Cádiz y su huella en América, Cádiz, Servicio de Publicaciones de la Universidad de Cádiz, 2011, p. 175.
} 
del régimen municipal. ${ }^{17}$ Con esta opinión, Suárez Suárez retoma el criterio que Francisco Carrera y Jústiz virtió poco más de cien años atrás: el texto constitucional español de 1812 había hecho vivir a la isla en "una vitalidad política vigorosísima". ${ }^{18}$

Llama la atención que, en la tradición de los autores referenciados, sólo dos sostengan la tesis contraria, más aún a la distancia de un siglo. De ahí, se desprenden las siguientes cuestiones: ¿gozó de vigencia real la Constitución española de 1812 en Cuba durante los años 1812 a 1814? ¿Pueden señalarse intentos conscientes por aplicarla y hacerla valer en el contexto social y político de la época? ${ }^{19}$

Una posible respuesta podría hallarse en los vestigios que la Constitución dejó a su paso por las poblaciones entonces existentes al interior de la isla, como la villa de Sancti Spíritus. Independientemente de aquellos resultados comunes, originados a lo largo del territorio insular, la llegada del constitucionalismo gaditano a Cuba debió producir recepciones conscientes y proactivas en las pequeñas localidades, como para merecer una atención particularizada. En 2012, Villabella Armengol expresó un punto de partida al respecto, al señalar que fue en los gobiernos interiores de los pueblos donde se sintieron los efectos más inmediatos de Cádiz en Cuba. ${ }^{20}$

El presente estudio aborda el proceso de recepción de la Constitución española de 1812 en la villa de Sancti Spíritus. Su elaboración se ha llevado a cabo sobre la base de la información existente en las actas capitulares del ayuntamiento, casi la única fuente documental que ha logrado sobrevivir la prueba del tiempo. Buena parte de la documentación anexa o colateral, generada por la actividad capitular, se ha perdido. La ausencia de imprenta en la villa durante el periodo estudiado explica la falta de una prensa local que pudiera servir de vehículo para el intercambio ideológico.

Sin desmedro del valor de otras fuentes, las actas capitulares del ayuntamiento suponen un valioso repositorio de información acerca de la administración

\footnotetext{
${ }_{17}$ Suárez Suárez, Reinaldo, "Repercusiones de la Constitución de Cádiz en Cuba (1812-1814), en Hitos constitucionales del siglo xix cubano, Camagüey, Ácana, 2011, p. 48.

${ }^{18}$ CarreRa y Jústiz, Francisco, Introducción a la historia de las instituciones locales en Cuba, tomo 2, La Habana, La Moderna Poesía, 1905, p. 179.

${ }^{19}$ Entre las valoraciones más actuales de la historiografia cubana respecto a la aplicación de la Constitución de Cádiz, resalta aquella que fundamenta su falta de vigencia en un supuesto interés de la oligarquía criolla de no hacerla valer. Sirva como ejemplo lo expresado por Limia en 2015: "La puesta en vigor de la Constitución tuvo un carácter más teórico que real, pues a la aristocracia habanera no le interesaba aplicar principios liberales que debilitaran su poder". Limia Diaz, ERnesto, Cuba Libre. La utopía secuestrada, La Habana, Verde Olivo, 2015, p. 87.

${ }^{20}$ Villabella Armengol, Carlos, "El constitucionalismo español en Cuba. La Constitución de Cádiz de 1812 y su repercusión en Cuba", en De Cádiz (1812) a La Habana (2012). Escritos con motivo del bicentenario de la Constitución española de 1812, La Habana, Universidad de La Habana - Universidad de Castilla La Mancha, 2012, p. 232.
} 
local. Ellas narran el día a día del ayuntamiento y, a la vez, atesoran los debates ideológicos suscitados entre los propios miembros de la corporación capitular. De igual modo, constituían el medio oficial que recogía y producía los lazos de comunicación con el gobierno superior y otras instituciones administrativas de la isla, así como con la propia metrópoli.

\section{Sancti Spíritus en el tiempo y la Constitución de Cádiz}

La villa de Sancti Spíritus formó parte del conjunto de poblaciones fundadas por el equipo conquistador del adelantado Diego Velázquez de Cuéllar, entre los años de 1510 y 1518. Su acto fundacional tuvo lugar en junio de 1514 $\mathrm{y}$, durante todo el siglo xVI, la joven población sufrió un crecimiento lento y tortuoso, contra el cual conspiró su condición geográfica de asentamiento de tierra adentro. En 1544, sólo se contaban en la villa veinte vecinos blancos, cifra que veinticinco años después, en 1569, permanecía inalterable. No obstante, para las postrimerías del siglo, se evidenció un ligero incremento de doscientos habitantes, sin distinguir raza o color. ${ }^{21} \mathrm{El}$ crecimiento demográfico era proporcional a la pobreza y las tempranas expresiones arquitectónicas así lo reflejaron: en 1620 la iglesia parroquial -con noventa años de existenciaaún se constituía de paja y madera. ${ }^{22}$

Aunque las cifras de mediados del siglo xvIII son inexactas, sugieren un mejoramiento de las condiciones económicas y de la situación de la sociedad. En 1760, Félix de Arrate visitó la villa, describió que tenía una población de tres mil vecinos, y que era productora de miel, aguardiente, tabaco y ganado. ${ }^{23}$ Para el censo de 1792, se contaban 2375 varones blancos -cifra similar a la enunciada por Arrate treinta años antes, quien posiblemente tomara su información del padrón vecinal-y un total de 10,496 habitantes, de los cuales se citaban 833 esclavos de ambos sexos. ${ }^{24}$ De tal manera, para fines del siglo xviII, la villa de Sancti Spíritus había experimentado un crecimiento económico y demográfico suficiente, hasta superar la situación de precariedad presente en el siglo XVI. ${ }^{25}$

\footnotetext{
${ }^{21}$ Del Moral, Luis, Historia de Sancti Spíritus, tomo 1, Las Villas, Iris, 1958, p. 190.

${ }^{22}$ Del Moral, Luis, Historia de Sancti Spiritus, tomo 1, Las Villas, Iris, 1958, p. 192.

${ }^{23}$ Arrate, José Martin Félix de, Llave del Nuevo Mundo, La Habana, Imagen Contemporánea, 2005, p. 101.

${ }^{24}$ Barrera Figueroa, Orlando, Estudios de historia espirituana, Sancti Spíritus, Luminaria, 1994, p. 67. Barrera disiente de esta cifra de esclavos y alude en el mismo texto que los 44 ingenios registrados en la villa para 1792 eran operados por 1100 esclavos, aunque sin señalar la fuente de la cual obtiene sus datos.

${ }^{25} \mathrm{El}$ censo llevado a cabo en la isla en 1817 contabilizó para la villa espirituana la cifra de 25941 habitantes. MARíN Garcia, Segundo, "Sancti Spiritus constitucional", Cuadernos Pérez Luna, núm. 6, p. 21.
} 
El texto constitucional de Cádiz llegó a la villa de Sancti Spíritus por vía extraoficial, en un pliego dirigido por el diputado a Cortes Andrés de Jáuregui, que fue abierto el 24 de julio de 1812 en la sala capitular. Junto al mismo, se recibieron también ejemplares de los decretos para el establecimiento de diputaciones y ayuntamientos constitucionales. Se acordó archivar esta documentación en espera de "que el Superior Govierno [sic] y Capitanía General de esta Isla lo prevenga”. ${ }^{26}$

La notificación oficial del nuevo estado de constitucionalidad no se hizo esperar mucho tiempo y la orden de su puesta en vigor fue asentada en el siguiente cabildo, el 31 de julio. Según recoge el acta de ese día, el texto constitucional fue leído in extenso por el secretario "en voz llana e intelegible [sic]", al igual que el resto de la documentación recibida que incluia "los tres reales decretos de establecimiento de Ayuntamientos en los pueblos en que no los hay, de Diputaciones Provinciales, y del indulto general" ${ }^{27}$ La misa solemne, juramentación pública y publicación del texto fueron acordadas para el catorce de agosto, sin embargo, a instancias de los capitulares, se convino abreviar la fecha para el día ocho, como prueba de "lo agradable que les ha sido y es la referida Constitución Política que han recivido [sic], acatado y obedecido en el mayor júbilo”. ${ }^{28}$ Así concurrieron las dos primeras actitudes de los espirituanos ante la llegada de la Constitución: la cautela primero y la simpatía después.

El recibimiento de la Constitución de Cádiz en Sancti Spíritus produjo un reordenamiento burocrático con efectos en los archivos capitulares. Para reseñar el funcionamiento de la nueva institucionalidad, se abrió un nuevo cuaderno de actas, aunque daba continuidad a la actividad capitular del año 1812, iniciaba sus folios en uno. Si bien se trata de un acto formal, sugiere que los operadores del cabildo local percibían que para la actividad municipal había llegado una nueva época. Un cuaderno de actas diferente era, por tanto, un gesto simbólico que marcaba la diferencia con el estado de cosas anteriores a la era constitucional.

\section{Primera elección de cargos e intentos de sabotaje}

La puesta en vigor de la Constitución de Cádiz precisaba la renovación inmediata de los cargos municipales existentes. ${ }^{29}$ El 15 de agosto, tuvo lugar

\footnotetext{
${ }^{26}$ Archivo Provincial de Historia de Sancti Spiritus, Acta de 24 de julio de 1812, Fondo, Ayuntamiento Colonia, legajo 9, fol. 75.

${ }^{27}$ Archivo Provincial de Historia de Sancti Spiritus, Acta de 31 de julio de 1812, Fondo, Ayuntamiento Colonia, legajo 9, fol. 78.

${ }^{28}$ Archivo Provincial de Historia de Sancti Spíritus, Acta de7 de agosto de 1812, Fondo, Ayuntamiento Colonia, legajo 9, fol. 80.

${ }^{29}$ Decreto CLXIV de 23 de mayo de 1812, Colección de los Decretos y Órdenes que han expedido las Cortes Generales y Extraordinarias desde 24 de septiembre de 1811 hasta 24 de mayo de 1812, tomo II, Madrid, Imprenta Nacional, 1820, pp. 221-224.
} 
el primer proceso eleccionario realizado en Sancti Spíritus sobre bases constitucionales y también el inicio de las disputas entre partidarios del nuevo orden municipal, contra las viejas autoridades del cabildo. Contrario a lo que preveía la normativa de las Cortes en materia de elecciones, ese día sólo fueron electos los cargos de regidores y síndico, pero no el de alcalde. El cargo se mantuvo en poder de quien había sido alcalde ordinario hasta ese momento: Higinio Fernández Morera.

Este incidente no pasó desapercibido. El recién electo síndico, secundado por uno de los nuevos regidores, se quejó ante la corporación capitular de que con la nueva legalidad debía cesar "todo oficio concegil [sic] de esta citada ya perpetuo y ya elegido por tiempo", lo cual incluía el puesto de la alcaldía. El resto de los vocales presentes evadieron el debate y concluyeron "que el Real decreto y artículo de la Constitución a que se contrae, que goviernan [sic] para este acto, no hablan expresamente de Alcaldes" y concluyeron que se elevaría la consulta al capitán general para que resolviera el caso. ${ }^{30}$

El juramento de los nuevos regidores y del síndico se llevó a cabo el 3 de septiembre ante el alcalde ordinario. Una vez posesionados en sus respectivos cargos, comenzó una puja electoral que duró hasta el 29 del propio mes, con el objetivo de que se renovara este puesto y se eligieran alcaldes constitucionales. Al día siguiente de jurar su puesto, el síndico Tomás de Pina arremetió contra los capitulares, culpándolos de violar el Real Decreto de 23 de mayo de 1812, que disponía la cesantía de los cargos de alcaldes, regidores y síndicos existentes, así como su renovación por elección. ${ }^{31}$ Acusaba a la corporación capitular de pervertir el orden público "por la falta de cumplimiento de una disposición soberana”, exigiendo la cesantía de "los oficios perpetuos los Alcaldes ordinarios de Hermandad, Síndico Comisaro [sic] de Policía y demás empleados”. ${ }^{32}$

Tres abogados fueron citados a concurrir con inmediatez a la misma sesión, para que emitieran su parecer respecto a la legitimidad de los cargos de alcalde existentes. De la información brindada por el acta de ese día, es presumible su complicidad para legitimar la alcaldía de Fernández Morera. Sin importar que el artículo 312 de la Constitución de Cádiz y su complementario Decreto cLXIII de 23 de mayo fuesen claros y visibles en materia electoral, dos de los letrados se las ingeniaron para interpretarlos del modo contrario. ${ }^{33}$

\footnotetext{
${ }^{30}$ Archivo Provincial de Historia de Sancti Spiritus, Acta de 15 de agosto de 1812, Fondo, Ayuntamiento Colonia, legajo 9, fol. 5. ${ }^{31}$ Archivo Provincial de Historia de Sancti Spíitius, Acta de 4 de septiembre de 1812, Fondo, Ayuntamiento Colonia, legajo 9, fol. 18. ${ }^{32}$ Archivo Provincial de Historia de Sancti Spíitus, Acta de 4 de septiembre de 1812, Fondo, Ayuntamiento Colonia, legajo 9, fol. 18. ${ }^{33}$ El Decreto CLXIII de 1812 sostenia: "Debiendo cesar en virtud de lo prevenido en el artículo 312 de la Constitución los Regidores y demás oficios perpetuos de Ayuntamiento, luego que se reciba y publique en cada Pueblo la Constitución y este decreto,...". Colección de los Decretos y Órdenes que han expedido las Cortes Generales y Extraordinarias desde 24 de septiembre de 1811 hasta 24 de mayo de 1812, tomo II, Madrid, Imprenta Nacional, 1820, p. 221.
} 
Uno de los juristas consultados, el licenciado José María Rodríguez, llegó a afirmar que "estando al literal tenor del artículo 312 de la Constitución política y a lo declarado por el Real Decreto de 23 de mayo de mil ochocientos doce no debieron cesar sino continuar como lo han hecho”. Otro, Luis de Cañizares, concluyó su declaración con la opinión de que no debían cesar de sus funciones los señores alcaldes. ${ }^{34}$

El debate producido escindió a los capitulares en dos bandos. Tres de los regidores se mostraron favorables a que Fernández Morera permaneciera en la alcaldía, mientras que cuatro pidieron la renovación del cargo. La alcaldía preconstitucional resistió mediante consultas dilatorias y la sesión terminó con acuerdo de consultar el parecer de la Real Audiencia, con sede en la villa de Puerto Príncipe. ${ }^{35}$

La contestación de la Capitanía General fue leída en la sesión siguiente del 10 de septiembre. Ésta afirmaba que "el espíritu de la Constitución ha sido renovar in totum los Ayuntamientos y sus Alcaldes a gusto y satisfacción del Pueblo elector [...] en este nuevo sistema debe guardarse uniformidad en toda la Ysla [sic] [...] y es necesario que la villa de Santo Espiritu [sic] haga lo mismo procediendo a la elección de Alcaldes ordinarios y de otro Síndico". ${ }^{36}$ La respuesta resultó concluyente, pero la reacción del cabildo no lo fue. Uno de los regidores, el licenciado Jacinto de Estrada, propuso que, sin faltar al acatamiento de lo dispuesto por el capitán general, se esperase la respuesta a la consulta hecha ante la Real Audiencia. El resto de los miembros de la corporación capitular aceptó la propuesta. ${ }^{37}$

El 25 de septiembre, se leyó la respuesta de la Real Audiencia. Al igual que la enviada desde la Capitanía General, conminaba a la celebración de elecciones. Paradójicamente, ninguno de los dos alcaldes concurrió al acto, a pesar que se trataba de una sesión ordinaria. Se envió por ellos al custodio de la cárcel, que hacía las veces de portero, pero éste regresó sólo con las excusas de los alcaldes para no concurrir. ${ }^{38}$ Esto fue una reacción visible de desacato al orden constitucional y una sublevación contra el cabildo.

\footnotetext{
${ }^{34}$ Solo uno, Fernando del Valle, afirmó "qe [sic] debieron cesar los Alcaldes y demás oficio. [sic] consiguientes fundado en el párrafo $3^{\circ}$ del mencionado RI. Dec ${ }^{\circ}$. [sic]".

${ }^{35}$ Hoy ciudad de Camagüey.

${ }^{36}$ Archivo Provincial de Historia de Sancti Spiritus, Documento anexo al acta de 10 de septiembre de 1812, Fondo, Ayuntamiento Colonia, legajo 9, fol. 23.

${ }^{37}$ Archivo Provincial de Historia de Sancti Spíitus, Acta de 10 de septiembre de 1812, Fondo, Ayuntamiento Colonia, legajo 9, fol. 23.

${ }^{38}$ Antonio María Venegas alegó no poder asistir al hallarse ocupado con un escribano en un trámite de negocios; mientras que Fernández Morera se excusó diciendo que no podía salir de su casa pues "se había lavado los pies con agua tibia en la noche inmedta. [sic] y no podía salir a la calle...". Archivo Provincial de Historia de Sancti Spiritus, Acta de 25 de septiembre de 1812, Fondo, Ayuntamiento Colonia, legajo 9, fol. 32.
} 
Los capitulares reaccionaron con duras críticas contra la gestión política y la actitud indiferente de Fernández Morera y Antonio María Venegas, frente al orden constitucional. Después, siguió lo que podría calificarse como un intento de deposición. En el texto del acta, se llegó a afirmar: "Este mismo Cuerpo está en la firme creencia de que ya cesaron sus funciones de Alcaldes y que deben ambos [...] concurrir a la entrega de las varas según es costumbre y tocando que se niegan a hacerlo se verá en el estrecho de depositarlas sin su concurrencia en los dos primeros Regidores". ${ }^{39}$ La amenaza les fue notificada de inmediato, según hizo constar el secretario.

Fue hasta el siguiente día, 26 de septiembre, que el segundo alcalde, José María Venegas, concurrió a presidir la sesión extraordinaria. ${ }^{40}$ En la misma, se impuso el sector constitucionalista y, tres días después -el 29 de septiembre-, se verificaba la primera elección constitucional de alcaldes y síndico procurador en Sancti Spíritus. Fueron electos ese día como alcaldes ordinarios José María Echemendía y Renzoli y Gregorio Pentón; para el cargo de síndico procurador, el licenciado, Pedro Carbó. ${ }^{41} \mathrm{Al}$ ser elegidos aquellos cargos que completaban la nómina para el gobierno local, quedó así conformado el ayuntamiento constitucional de la villa.

La puja por constitucionalizar la alcaldía de Sancti Spíritus refleja el enfrentamiento que se produjo en las poblaciones cubanas del interior, entre los partidarios del sistema constitucional y sus detractores, quienes optaron por el sabotaje institucional. En el fondo de la pugna, latía un importante aliciente. Cargos como el de alcalde ordinario de la villa habían sido adquiridos por compra y, en sí mismos, eran símbolos del poder de las pequeñas oligarquías locales sobre los ayuntamientos. El interés por mantenerlos secuestrados llegó al intento de desacatar una orden del capitán general y un auto consultivo de la Real Audiencia de Puerto Príncipe. Solo la presión ejercida por el núcleo constitucionalista local fracturó su resistencia.

El hecho descrito cuestiona las valoraciones, en la historiografía cubana, acerca del bajo perfil de la Constitución de Cádiz en el contexto de los ayuntamientos locales. Evidencia, además, la existencia de un determinado sector social con voluntad para hacerla efectiva en todos los órdenes posibles. En algunos casos, como el presente, con éxito.

\footnotetext{
${ }^{39}$ Archivo Provincial de Historia de Sancti Spíitus, Acta de 25 de septiembre de 1812, Fondo, Ayuntamiento Colonia, legajo 9 , fol 36.

${ }^{40}$ Archivo Provincial de Historia de Sancti Spiritus, Acta de 26 de septiembre de 1812, Fondo: Ayuntamiento Colonia, legajo 9, fol. 45.

${ }^{41}$ Ídem. fol. 52.
} 


\section{El bienio constitucional para el ayuntamiento de Sancti Spíritus}

La validez de un texto constitucional no depende únicamente de la realización de aquellos procesos electorales prescritos en su normativa. Éstos, en todo caso, sólo sirven para legitimar las nuevas estructuras de gobierno creadas o reformadas por la misma normativa, en función de quien dimana la soberanía. La Constitución de Cádiz había modificado el procedimiento para la renovación de los cargos de ayuntamiento, haciéndolo más participativo, de acuerdo con la fórmula electoral presente en la propia Constitución. Sin embargo, ello sólo lograría adquirir sentido en la medida en que tal reforma incidiese en una mayor descentralización de las administraciones locales. De lo contario, daría lo mismo que los ciudadanos eligieran los cargos de ayuntamiento o que éstos fueran designados por la Corona o las Cortes.

El espíritu presente en el constituyente gaditano y en el legislador de los decretos de Cortes, para la instauración de gobiernos municipales, apuntaba hacia la legitimación de determinados espacios de independencia funcional que coadyuvaran a dinamizar la vida local. De ahí que, en el marco de su vigencia, determinados sectores locales se valieran de la normativa constitucional para justificar la construcción de determinadas metas sociales. Por tanto, una pregunta obligada sería: ¿los nuevos funcionarios elegidos para el ayuntamiento constitucional supieron captar este ánimo descentralizador? En la correspondencia entre la actuación de los nuevos ayuntamientos con este espíritu, se puede hallar la respuesta acerca de cuál fue la efectividad directa que el texto constitucional gaditano tuvo sobre los gobiernos locales de Cuba, durante su primer periodo de vigencia. El ayuntamiento constitucional de Sancti Spíritus se puede tomar como objeto de estudio para este caso. ${ }^{42}$

Las autoridades constitucionales recién electas intentaron hacer valer las prerrogativas administrativas que el texto de 1812 confería a los ayuntamientos. De hecho, al contrastar el contenido de las cuestiones que los capitulares debatieron entre 1800 y 1812 , se aprecia un giro sustancial en su postura respecto a la solución de los problemas locales. Problemáticas que, hasta ese momento, estaban ausentes del seno de los debates capitulares comenzaron a hacerse frecuentes. Ello sugiere que el sector constitucionalista espirituano pretendió valerse del nuevo orden impuesto, para fortalecer la administración

\footnotetext{
${ }^{42}$ La historiadora cubana Olga Portuondo ha sostenido la opinión contraria. Al comentar el artículo 321 de la Constitución de Cádiz, que regulaba las funciones de los ayuntamientos, afirma que "De ninguna manera la oligarquía criolla de América, incluso la de la Isla de Cuba, podia simpatizar con buena parte de una legislación que limitaba sus poderes ancestrales de autodeterminación". Portuondo ZúÑIGA, OLga, Cuba, Constitución y liberalismo, tomo 1, Santiago de Cuba, Oriente, 2008, p. 78.
} 
y el gobierno local. El artículo 321 de la Constitución se convirtió para éstos en un referente normativo y legitimador de su gestión.

Uno de los efectos más visibles del orden constitucional gaditano en las poblaciones cubanas del interior debió estar relacionado con las cuestiones de infraestructura local. Asentamientos como Sancti Spíritus carecían de un puerto marítimo cercano y ello influía sensiblemente en el mantenimiento de las comunicaciones y el comercio. Tal situación se agravaba por la precariedad en que se encontraban los caminos de la época. Durante el siglo xvi, esta realidad había sido una de las causas para la virtual incomunicación de las villas del centro de Cuba con el gobierno de La Habana. De hecho, en la propia época constitucional, los despachos oficiales enviados desde la Capitanía General eran conducidos por mar hasta la villa de Trinidad y, desde allí, se hacía el camino terrestre hasta Sancti Spíritus. De tal manera, en el año en que la Constitución de Cádiz entró en vigor, la navegación de cabotaje seguía siendo la opción preferible para el despacho de comunicaciones oficiales, en lugar de los caminos públicos.

Para 1812, Sancti Spíritus poseía diez caminos públicos, de los cuales, tres conducían a los centros urbanos donde radicaban las dependencias oficiales: el camino real de La Habana, el real de Trinidad -sede de la tenencia de gobernación- y el real de Puerto Príncipe, lugar donde tenía su asiento la Real Audiencia de la Isla. ${ }^{43}$ En la sesión ordinaria del 30 de octubre de 1812, las autoridades constitucionales de la villa discutieron la situación de las vías territoriales de comunicación y acordaron dar "el más exacto cumplimiento a la nueva Constitución”, en lo relativo a la construcción y reparación de caminos. ${ }^{44}$

Las referencias sobre la discusión de ese día permiten inferir que la situación de los caminos con que contaba la villa era precaria. En consecuencia, las autoridades del cabildo

dispusieron que quanto [sic] antes se salga por los dos Señores Presidentes y Compañero y Comisarios que se iran [sic] nominando a la apertura de dichos Caminos y composición de su piso por el orden que mejor corresponda, dándose a los que son reales el ancho de veinte y quatro [sic] varas castellanas, y el de dies y seis [sic] a los transversales sin perjuicio de hacerlos extender mas en aquellos parages [sic] particulares

\footnotetext{
${ }^{43}$ Los otros caminos tenían carácter local y conducian al resto de las demarcaciones territoriales de la villa. ARCHIvo ProvinciaL de Historia de Sancti Spiritus, Acta de 30 de octubre de 1812, Fondo, Ayuntamiento Colonia, legajo 9, fol. 104-105.

${ }^{44}$ Véase Constitución Política de la Monarquía Española de 1812, Artículo 321. Colección de los Decretos y Órdenes que han expedido las Cortes Generales y Extraordinarias desde 24 de septiembre de 1811 hasta 24 de mayo de 1812, tomo II, Madrid, Imprenta Nacional, 1820, pp. 98-164.
} 
en que sea preciso porque el ámbito designado no sea bastante a desechar alguna maleza incomponible que se encuentre. ${ }^{45}$

Con el fin de comprometer a la élite militar local, se emitió una notificación al comandante de Armas, a fin de que compeliese a los aforados de milicias a que prestasen también su colaboración en las obras de caminos. ${ }^{46}$

Un elemento que evidencia la voluntad capitular para materializar las potestades constitucionales conferidas a los nuevos ayuntamientos puede encontrarse en el acta de 14 de diciembre de 1812. Ésta da cuenta de que se recibió la Real Orden de 13 de septiembre del propio año, la cual mandaba informar al gobierno superior acerca del estado de los caminos, pantanos, puentes, etcétera. Además, la misma pedía que se informara de lo necesario para acometer las dichas obras de reparación.

La comparación entre ambas actas sugiere que, con poco más de un mes de antelación a la llegada de la referida Real Orden, el nuevo ayuntamiento -amparado únicamente en la letra del artículo 321 de la Constitución- había decidido mutuo proprio acometer la tarea de reparación de caminos. Este hecho indica el compromiso de los nuevos capitulares para legitimar constitucionalmente la resolución de las problemáticas locales.

El 18 de diciembre de 1812, el ayuntamiento constitucional, apoyado en los apartados primero y segundo del artículo 321 del texto gaditano, ${ }^{47}$ arremetió contra la expedición de bebidas en los establecimientos comerciales existentes. En una extensa declaración, el regidor Rafael Rodríguez Venegas se quejaba de la falta de control sobre el funcionamiento de las tabernas y pulperías existentes en la villa. Afirmaba que éstas violaban lo dispuesto por los bandos de policía y buen gobierno, en relación con el modo en que debían efectuarse las ventas al público. ${ }^{48}$ A continuación, enumeraba una sarta de disturbios sociales originados, según su parecer, por la venta ilegal de bebidas alcohólicas a cualquier hora y en plena calle, así como por la concurrencia del lumpen local.

\footnotetext{
${ }^{45}$ Archivo Provincial de Historia de Sancti Spiritus, Acta de 30 de octubre de 1812, Fondo, Ayuntamiento Colonia, legajo 9, fol. 105.

${ }^{46}$ Archivo Provincial de Historia de Sancti Spiritus, Acta de 30 de octubre de 1812, Fondo, Ayuntamiento Colonia, legajo 9, fol. 105.

47 "Estará a cargo de los ayuntamientos [...] Primero: la policía de salubridad y comodidad. Segundo: Auxiliar al alcalde en todo lo que pertenezca a la seguridad de las personas y bienes de los vecinos, y a la conservación del orden público." Constitución Política de la Monarquía española de 1812, Artículo 321, apartados primero y segundo. Colección de los Decretos y Órdenes que han expedido las Cortes Generales y Extraordinarias desde 24 de septiembre de 1811 hasta 24 de mayo de 1812, tomo II, Madrid, Imprenta Nacional, 1820.

${ }^{48}$ Archivo Provincial de Historia de Sancti Spíritus, Acta de 18 de diciembre de 1812, Fondo, Ayuntamiento Colonia, legajo 9, fol. 127.
} 
El cierre de la sesión terminó con la decisión del cabildo de ordenar que, en un plazo de seis días, se colocara un mostrador a la entrada de cada taberna, con el fin de expender las mercancías, sin permitir la entrada de los clientes al lugar. ${ }^{49}$ La contravención de esta decisión estuvo sancionada, la primera vez, por el pago de cuatro ducados, si fuera un hombre, y hasta cincuenta ducados en caso de hallarse personas de ambos sexos dentro del recinto.

Más allá de los elementos de hecho mencionados en la declaración, existían fundamentos jurídicos preexistentes como para que el ayuntamiento ejerciera control y fiscalización sobre esta clase de establecimientos. El 21 de julio de 1803, Carlos IV había publicado un bando que sancionaba a penas de multa, trabajos forzados y prisión, a quienes pronunciaran blasfemias, maldiciones o palabras obscenas en la calle o en lugares públicos. Según el artículo tercero de este mandato, los dueños de tabernas, juegos de billar, cafés, y otros, serían responsables de la falta de observancia de las prohibiciones mencionadas, por lo cual se les imponía la pena de cierre de sus establecimientos. ${ }^{50}$

El gremio de pulperos y taberneros de la ciudad tardó en emitir su queja el tiempo suficiente para dejar pasar las fiestas de año nuevo. El 8 de enero del año entrante (1813), su súplica fue leída en la sala capitular, donde pedían que les fuera retirada la prohibición de colocar mostrador en las puertas de sus tiendas y pulperías "conforme al bando de buen gobierno y practica [sic] de la capital". ${ }^{51}$ Del texto citado, resalta que el bando de buen gobierno y policía invocado por el ayuntamiento era conocido en la villa y, aun así, los pulperos suplicaron que no se aplicase. Una petición como ésta evidencia una tradición de desacato, en la conciencia colectiva. Como respuesta, el ayuntamiento declaró sin lugar la súplica y eximió de la prohibición, únicamente, a los almacenes que vendian al detalle. ${ }^{52}$

Casi un mes después, el 5 de febrero, los pulperos y taberneros arremetieron con un memorial donde exigían nuevamente que se aboliera la prohibición de vender con rejas y mostrador. Sin embargo, el texto poseía fundamentos distintos al de la súplica del 8 de enero. Si en ésta pedían que no se aplicase el bando de policía y buen gobierno, en el memorial, exigían que se aplicase correctamente la nueva Constitución, acusando la medida de inconstitucional. Para ello,

\footnotetext{
${ }^{49}$ Archivo Provincial de Historia de Sancti Spiritus, Acta de 18 de diciembre de 1812, Fondo, Ayuntamiento Colonia, legajo 9, fol. 128.

${ }^{50}$ ESCRICHE, JoAquin, Diccionario razonado de legislación y jurisprudencia, Paris, Libreria de Rosa, 1852, p. 627.

${ }^{51}$ Archivo Provincial de Historia de Sancti Spiritus, Acta de 8 de enero de 1813, Fondo, Ayuntamiento Colonia, legajo 11, fol. 1.

${ }^{52}$ Archivo Provincial de Historia de Sancti Spiritus, Acta de 15 de enero de 1813, Ayuntamiento Colonia, legajo 11, fol. 2.
} 
sostenían que la decisión era contraria a la Constitución "en la parte que impone el gravamen de rexas [sic] en sus Pulperías bajo multas arbitrarias". ${ }^{53}$

La polémica debió girar en torno a la ambigüedad del apartado primero del artículo 321, del texto constitucional gaditano. En éste, se encargaba a los ayuntamientos "la policía de salubridad y comodidad". Además de esta formulación, la Constitución no entraba en detalles. Como resultado final, el ayuntamiento acordó mantener la medida y devolver a los reclamantes el documento original, dejando copia archivada.

Este hecho demuestra cómo, en poco tiempo, la Constitución de Cádiz comenzó a ser invocada por los habitantes de la villa para resolver sus querellas. Independientemente de los posibles partidismos favorables y contrarios al nuevo régimen, así como del sentido oportunista con el cual se podía invocar el texto doceañista, el hecho en sí prueba que la joven Constitución política no pasó desapercibida, ni tampoco fue objeto de la indiferencia local.

En el mes de octubre, el cabildo espirituano recibió la Instrucción de las Cortes para el gobierno económico-político de los ayuntamientos constitucionales, de 23 de junio de $1813 .{ }^{54}$ Esta norma era el complemento al título dedicado a los ayuntamientos en la Constitución de Cádiz y fue derogada por una de igual nombre en 1823. En Cuba, tuvo una vigencia más corta que la del propio texto gaditano. Trece meses después de su llegada, los ayuntamientos constitucionales fueron disueltos.

En la literatura revisada no consta ninguna referencia a los posibles intentos de aplicabilidad de tal instrucción en Cuba. Ni siquiera un texto como Cuba. Constitución y liberalismo, dedicado por entero a las repercusiones de Cádiz en la isla, la menciona. Sin embargo, la documentación del ayuntamiento constitucional de Sancti Spíritus sugiere una voluntad proactiva, por haberla implementado en soluciones de orden práctico.

El catorce de octubre - a sólo cinco días de recibida la Instrucción- el alcalde constitucional convocó a cabildo extraordinario. Ello tenía por objeto responder a un oficio del fiscal del Protomedicato de la villa, relativo a los efectos nefastos que sufría la población por causa de una epidemia de fiebres que la asolaba desde el mes de julio. Los capitulares, amparados en el artículo 4 de la Instrucción de 1813, acordaron la formación de una Junta de Sanidad, compuesta por el alcalde primero, el párroco, uno o más facultativos, regidores

\footnotetext{
${ }^{53}$ Archivo Provincial de Historia de Sancti Spíitus, Documento anexo al acta de 5 de febrero de 1813, Fondo, Ayuntamiento Colonia, legajo 11, fol. 9.

${ }^{54}$ Archivo Provincial de Historia de Sancti Spíritus, Acta de 8 de octubre de 1813, Fondo, Ayuntamiento Colonia, legajo 11, fol. 92.
} 
y vecinos. ${ }^{55}$ Dada la urgencia de las circunstancias, el alcalde ordenó la creación de la primera de estas juntas, formada por el cura párroco, los regidores del ayuntamiento y dos médicos, para que comenzaran sus trabajos el mismo día, dieciocho de ese mes de octubre.

En materia de salud pública, el ayuntamiento constitucional espirituano intentó ampliar su radio de acción. Sólo tres meses después de creada la Junta de Sanidad y de haberse recibido la nueva Instrucción, el ayuntamiento intervino en la administración del hospital de la villa, hasta ese momento regenteado por la Iglesia.

Para legitimar esta intervención, parte de las autoridades del ayuntamiento exhibió una fraseología marcadamente constitucional, síntoma del cambio que operó el orden gaditano en el discurso y conciencia política de los nuevos funcionarios. Respecto al tipo de subordinación al que debía encontrarse sujeto el hospital de la villa, el alcalde alegó que su fundación era real y no eclesiástica, independientemente de que fuera la Iglesia quien lo administrara. Para ello, expresaba que las rentas con las cuales se sufragaba la instalación consistían "en mucha parte de los diezmos que deben reputarse en el día como Nacionales, respecto que lo que antes se decía Patrimonio Real o de la Corona en el nuevo orden se entiende de la Nación: que si la Corona antes encomendó a la potestad Eclesiasica [sic] el gobierno de semejante fundación total o parcialmente, la Nacion [sic] lo ha confiado ahora a los Ayuntamientos. ${ }^{56}$ Aunque el alcalde constitucional de la villa no citaba al texto gaditano, sus argumentos hacen referencia al apartado sexto del artículo 321, que establecía para los ayuntamientos la obligación de cuidar de los hospitales y demás establecimientos de beneficencia.

Entre el 19 de abril y el 13 de mayo, el ayuntamiento llevó a cabo un serio intento por institucionalizar con normas propias su gestión local. En cumplimiento del apartado octavo del artículo 321 de la Constitución, los capitulares acordaron la formación del conjunto de ordenanzas municipales que debían regir la vida de la localidad. Para la redacción del borrador fueron nombrados, en calidad de comisarios, dos miembros de la corporación capitular. Se les otorgaron plenos poderes para reclamar el apoyo de cualquiera de los demás capitulares "y de aquellos vecinos que les parescan [sic] mas a propósito por su idoneidad y talento". ${ }^{57}$

\footnotetext{
${ }^{55}$ Archivo Provincial de Historia de Sancti Spiritus, Acta de 14 de octubre de 1813, Fondo, Ayuntamiento Colonia, legajo 11, fol. 94.

${ }^{56}$ Archivo Provincial de Historia de Sancti Spiritus, Acta de 14 de enero de 1814, Fondo, Ayuntamiento Colonia, legajo 11, fol. 1.

${ }^{57}$ Archivo Provincial de Historia de Sancti Spíitus, Acta de 19 de abril de 1814, Fondo, Ayuntamiento Colonia, legajo 11, fol. 33.
} 
La vida municipal cubana estaba regida para entonces por dos cuerpos normativos fundamentales: las ordenanzas redactadas por el oidor Alonso de Cáceres en $1574^{58}$ y la Instrucción General para Capitanes y Tenientes de Partido, mandada a redactar por el capitán general José de Ezpeleta, en junio de 1786. La primera había sido creada hacía más de doscientos años y la segunda poseía objetivos muy específicos, pues se ocupaba solamente de regular las funciones de los capitanes de partido.

Sin contar los preceptos de la dispersa legislación de Indias, los ayuntamientos carecían de regulaciones propias para su actividad. Con la Constitución de Cádiz, en cambio, se les permitía redactar y elevar sus propias ordenanzas a la Diputación Provincial, para su aprobación. Éste debió ser uno de los elementos valorados por Carrera y Jústiz al momento de afırmar que, con el constitucionalismo gaditano, la vida municipal en la isla había adquirido "una vitalidad política vigorosísima". ${ }^{59}$

El 13 de mayo de 1814, los comisionados del ayuntamiento constitucional espirituano rindieron cuenta de su labor. En presencia de los demás capitulares, dieron lectura al borrador de las primeras ordenanzas municipales de la villa. El documento original no ha sido encontrado y sólo consta la reseña del secretario del ayuntamiento en el cuaderno capitular. Por estas anotaciones, se puede conocer que las mismas pretendían regular cuestiones relacionadas con la policía, el comercio, la impartición de justicia y el control de armas dentro de la población.

En la reseña del secretario, resalta como elemento adicional la referencia que hicieron los comisionados a la Instrucción para el gobierno económico-político de las provincias de 1813. Ello sugiere que las proyectadas ordenanzas debían fungir como legislación complementaria a la referida instrucción. ${ }^{60}$ Frente a los criterios de negación que rodean la vigencia de la legislación gaditana en Cuba, este hallazgo demuestra la existencia de consenso en torno a ella y una voluntad proactiva para hacerla cumplir.

A partir del mes de julio, la actividad del ayuntamiento constitucional espirituano entró en un proceso de desaceleración progresiva. El 29 de ese mes, se notificó al ayuntamiento la instalación de Fernando VII en el trono, y el 12 de agosto, llegaba a la villa la declaratoria de nulidad para todos los

\footnotetext{
${ }^{58}$ Estas ordenanzas regian todavía en Cuba tras el fin de los dos primeros periodos constitucionales. En 1827 fueron reimpresas oficialmente como ordenanzas municipales de La Habana para uso del ayuntamiento. Vid. Ordenanzas Municipales de la Ciudad de La Habana, La Habana, Imprenta del Gobierno y Capitanía General, 1827.

${ }^{59}$ CarreRa y Jústiz, Francisco, Introducción a la historia de las instituciones locales en Cuba, tomo 2, La Habana, La Moderna Poesía, 1905, p. 179.

${ }^{60}$ Archivo Provincial de Historia de Sancti Spiritus, Acta de 13 de mayo de 1814, Fondo: Ayuntamiento Colonia, legajo 11, fol. 49 .
} 
actos realizados bajo el gobierno de la Regencia y de las Cortes. La noticia fue recibida a través de un despacho enviado desde la tenencia de gobernación, con sede en la ciudad de Trinidad. El mismo acompañaba a una copia del Diario de la Habana, de 21 de julio, donde se reproducía el decreto fernandino del 4 de mayo. ${ }^{61}$

La reacción de los capitulares sugiere una profunda conmoción, pues el ayuntamiento no volvió a sesionar hasta el 2 de septiembre. Durante el resto de ese mes, y hasta el 21 de octubre, sólo aparecen en el cuaderno capitular las anotaciones del secretario que acreditan la suspensión de las sesiones del cabildo por ausencia de sus miembros. Las sesiones posteriores a esa fecha ocupan poco más de una cuartilla y tienen como único objetivo responder a solicitudes relativas a mercedes de solares y fincas rústicas.

El 21 de noviembre, se produjo el acto de cierre del ayuntamiento constitucional de Sancti Spíritus. Ante la concurrencia de todos sus miembros, se leyó un oficio del capitán general, así como la Real Cédula de 30 de julio, que mandaba la "disolución de los Ayuntamientos que se llamaron Constitucionales, y la reposición de los perpetuos". ${ }^{62}$ En el mismo acto, se citó a los antiguos funcionarios del cabildo y, en ceremonia realizada el propio día, se les reintegró en sus asientos y cargos "quedando en su virtud disuelto el Ayuntamiento que se llamó Constitucional”. ${ }^{63}$

\section{Conclusión}

La Constitución de Cádiz fue recibida en Cuba con acatamiento y las probabilidades para ello resultaban altas. La isla formaba parte del conglomerado territorial que entonces componía la monarquía hispánica. De ahí que toda la legislación dictada para ejecutarse a lo largo de la misma le resultara de obligatorio cumplimiento. Con independencia del contexto histórico de excepcionalidad que vivía la monarquía española por entonces, el texto doceañista llegó a Cuba como norma que debía ponerse en vigor, y así ocurrió.

La situación de fidelidad en que se mantuvo la oligarquía criolla de la isla ante la metrópoli contribuyó a la efectividad práctica de la norma. Cuba no formó parte del movimiento independentista hispanoamericano y el intento por crear una junta de gobierno en La Habana fracasó en el propio año de 1808. Por

\footnotetext{
${ }^{61}$ Archivo Provincial de Historia de Sancti Spiritus, Acta de 12 de agosto de 1814, Fondo, Ayuntamiento Colonia, legajo 11, fol. 68.

${ }^{62}$ Archivo Provincial de Historia de Sancti Spíritus, Acta de 21 de noviembre de 1814, Fondo, Ayuntamiento Colonia, legajo 11, fol. 81.

${ }^{63}$ Archivo Provincial de Historia de Sancti Spíritus, Acta de 21 de noviembre de 1814, Fondo, Ayuntamiento Colonia, legajo 11, fol. 81.
} 
tanto, acatar y promulgar la carta gaditana suponía -a la vez que una prueba de fidelidad- una solución objetiva al vacío de poder que había dejado el rey.

Para las élites políticas locales, la promulgación y vigencia de La Pepa en Cuba no pasaron inadvertidas. De hecho, se puede afirmar que, entre las mismas, existieron sectores abiertamente constitucionalistas, donde caló la voluntad por hacer efectivos sus postulados. Ello debió ser particularmente visible en las localidades del interior de la isla, las cuales se habían mantenido en una situación de desarrollo desfavorable respecto a La Habana. Tal fue el caso de Sancti Spíritus, donde el breve ayuntamiento constitucional optó por optimizar el plexo de potestades conferidas por el régimen gaditano, desde posiciones de descentralización. 


\section{Bibliografía}

Archivo Histórico Provincial de Sancti Spíritus, Fondo, Ayuntamiento - Colonia, legajos 9 y 11 (1812-1814).

ArRate, José Martín Félix de, Llave del Nuevo Mundo, La Habana, Imagen Contemporánea, 2005.

Bachiller y Morales, Antonio, Apuntes para la Historia de las letras y de la instrucción pública en la Isla de Cuba, tomo 2, La Habana, Imprenta del Tiempo, 1860.

Barrera Figueroa, Orlando, Estudios de historia espirituana, Sancti Spíritus, Luminaria, 1994.

Carreras, Julio, Historia del Estado y el Derecho en Cuba, La Habana, Pueblo y Educación, 1989.

Carrera y Jústiz, Francisco, Introducción a la historia de las instituciones locales en Cuba, tomo 2, La Habana, La Moderna Poesía, 1905.

Colección de los Decretos y Órdenes que han expedido las Cortes Generales y Extraordinarias desde 24 de septiembre de 1811 hasta 24 de mayo de 1812, tomo Il, Madrid, Imprenta Nacional, 1820.

Chust, Manuel, "La revolución bihemisférica de la Constitución de 1812", Teoría y Derecho: revista de pensamiento jurídico, núm. 10.

Del Moral, Luis, Historia de Sancti Spíritus, tomo 1, Las Villas, Iris, 1958.

Escriche, Joaquín, Diccionario razonado de legislación y jurisprudencia, París, Librería de Rosa, 1852.

Fernández Sarasola, lgnacio, "La Constitución española de 1812 y su proyección europea e iberoamericana”, Fundamentos. Cuadernos monográficos de Teoría del Estado, Derecho Público e Historia Constitucional, núm. 2. Disponible en: http://www. uniovi.es/constitucional/fundamentos/segundo

Ferrer Muñoz, Manuel, La Constitución de Cádiz y su aplicación en la Nueva España, México, unam, 1993.

Guerra Vilaboy, Sergio, "La Constitución Gaditana en Cuba: 1812-1823", en La Constitución de Cádiz y su huella en América, Cádiz, Servicio de Publicaciones de la Universidad de Cádiz, 2011.

Guiteras, Pedro José, Cuba y su gobierno. Con un apéndice de documentos históricos, Londres, Imprenta de C. Wood, 1853.

Guiteras, Pedro José, Historia de la Isla de Cuba, volumen 2, La Habana, Imagen Contemporánea, 2005.

Hernández Corujo, Enrique, Historia Constitucional de Cuba, tomo 1, La Habana, Compañía Editora de Libros y Folletos, 1960.

InFIeSTA, Ramón, Historia Constitucional de Cuba, La Habana, Cultural, 1951.

limia Díaz, ERnesto, Cuba Libre. La utopía secuestrada, La Habana, Verde Olivo, 2015. Marín García, Segundo, "Sancti Spíritus constitucional”, Cuadernos “Pérez Luna”, núm. 6. 